\title{
PENURUNAN KADAR ASAM URAT SETELAHPEMBERIAN REBUSAN DAUN SALAM PADA LANSIA
}

\author{
Santi Novitasari ${ }^{1}$, Ricky Riyanto Iksan $^{2^{*}}$, Sri Atun Wahyuningsih ${ }^{3}$ \\ 1,2,3Program Studi Diploma Tiga Keperawatan Akademi Keperawatan Pelni \\ Email Korespondesi: kykyiksan@gmail.com
}

\section{ABSTRACT : THE DECREASE OF URIC ACID LEVELS AFTER GIVING SALAM LEAVES BOOKIN IN ELDERLY}

Background: Gout is dominant health problem in many countries, both in developed countries and in depeloping countries, , although the prevalence rate of gout in the world globally has not been recorded. The increase in the incidence of gout arthritis does not only occur in developed countries. Signs and symptoms are inflammation in the depressed joints, pain, and redness in areas that have occurred gout, strength and swelling in the depressed joint. Objective : the study to identify the effect of therapy in the administration of salam leaf water decoction on the decrease in uric acid levels for the elderly.

Method : This type of research is a case study design, is a form of research (inquiry) or case study in 4 elderly people who suffer from gout and intervention about a problem that has specialty properties in the elderly.

Results : The results of the study conducted decreased uric acid levels in the elderly after being given a stew of salam leaves with an average value of 6.0 $\mathrm{mg} / \mathrm{dl}$.

Conclusion: the study of the decoction of salam leaves is given 2 times a day as many as 10 sheets of salam leaves, in this study gout sufferers have shown a significant decrease in uric acid levels on the sixth day.

Keywords : Elderly, Gout, Salam Leaves, Uric Acid Levels, Case study

\section{INTISARI : PENURUNAN KADAR ASAM URAT SETELAH PEMBERIAN REBUSAN DAUN SALAM PADA LANSIA}

Latar Belakang : Gout merupakan suatu masalah kesehatan yang dominan diberbagai negara, baik di negara - negara maju maupun di negara - negara berkembang,meskipun angka prevalensi gout di dunia secara global belum tercatat. Peningkatan kejadian gout arthritis tidak hanya terjadi di negara maju saja. Tanda dan gejala yaitu peradangan pada sendi yang tertekan, terasa nyeri, dan kemerahan pada daerah yang telah terjadi asam urat, kekuatan serta pembengkakan pada sendi yang tertekan.

Tujuan : Penelitian Ini bertujuan teridentifikasi pengaruh terapi pemberian rebusan air daun salam terhadap penurunan kadar asam urat bagi lansia.

Metode Penelitian : Jenis penelitian ini adalah case study design yaitu suatu bentuk penelitian (inquiry) atau studi kasus dan intervensi tentang suatu masalah yang memiliki sifat kekhususan (particularty).

Hasil : penelitian yang dilakukan mengalami penurunan kadar asam urat pada lansia setelah diberikan rebusan daun salam dengan rerata nilai $6,0 \mathrm{mg} / \mathrm{dl}$. 
Kesimpulan : penelitian pemberian rebusan daun salam diberikan 2 kali sehari sebanyak 10 lembar daun salam, pada penelitian ini penderita asam urat telah menunjukan penurunan kadar asam urat yang signifikan pada hari ke enam.

Kata Kunci : Asam Urat, Daun Salam, Kadar Asam Urat, Lansia, Study kasus

\section{PENDAHULUAN}

Gout merupakan suatu masalah kesehatan yang dominan diberbagai negara, baik di negara negara maju maupun di negara negara berkembang, meskipun angkaprevalensi gout di dunia secara global belum tercatat. Menurut World Health Organization (WHO) tahun 2017 pravelensi penyakit gout arthritis terjadi sebanyak $34,2 \%$. Gout arthritis sering terjadi di negara maju seperti amerika. Prevalensi gout arthritis di Negara amerika. Peningkatan kejadian gout arthritis tidak hanya terjadi di negara maju saja. Namun, peningkatan

juga terjadi di negara berkembang, salah satunya di Negara Indonesia (Eni et al., 2018)

Prevalensi di dunia penderita gout artritis mengalami kenaikan jumlah penderita hingga dua kali lipat antara tahun 1990-2010. Pada orang dewasa di Amerika Serikat penyakit gout mengalami peningkatan danmempengaruhi 8.3 juta (4\%) orang Amerika. Sedangkan prevalensi hiperurisemia juga meningkat dan mempengaruhi $43.300 .000(21 \%)$ orang dewasa di Amerika Serikat. Penelitian di Taiwan tahun 2013 prevalensi penyakit gout artritis sebesar $41,4 \%$ dan meningkat sebesar $0,5 \%$ setia tahun. Penyakit gout artritis diperkirakan terjadi pada 840 orang dari setiap 100.000 orang. (Jaliana et al.,2018).

Prevelensi penyakit asam uratdi Indonesia semakin mengalami peningkatan. Menurut Riskesdas tahun 2018, prevalensi penyakit asam urat berdasarkan diagnose tenaga kesehatan dilndonesia 11,9\% dan berdasarkan diagnosis atau gejala $24,7 \%$ jika dilihat dari karateristikumur, prevalensi tinggi pada umur $\geq 75$ tahun $(54,8 \%)$. Penduduk umur $\geq 15$ Tahun didapatkan hasil bahwa pada kelompok umur 65 tahun yang menderita penyakit sendi berjumlah 56.394 orang. Satu surveiepidemiologik yang dilakukan di Bandung, Jawa Tengah terhadap 4.683 sampel berusia antara 15 - 45 tahun didapatkan bahwa prevalensi gout pada wanita sebesar $11,7 \%$. (Kementrian Kesehatan RI, 2018). Dinas kesehatan DKI Jakarta tahun 2018 di perkirakan 47,83\% lansia yang mengidap penyakit asam urat sedangkan untuk prevalensi penderita asam urat di wilayah Jakarta Barat sebanyak 6,38\%. Berdasarkan data tersebut wilayah Jakarta Barat merupakan daerah yang menempati

posisi keempat terendah setelah Jakarta Selatan untuk lansia yang menderita asam urat. (sudinkes DKI Jakarta Barat, 2018)

Tanda dan Gejala Asam Urat pada lansia menurut Setianingrum et al., 2017 yaitu perada pada sendi yang tertekan, terasa nyeri, dan kemerahan pada daerah yang telah terjadi asam urat, kekuatan serta pembengkakan pada sendi yang tertekan. Seiring terjadinya proses penuaan dan pola makan yang tidak sehat dengan banyakmengkonsumsi makan tinggi purin serta obesitas dapat menyebabnya peningkatan kadar asam urat sehinggalansia tidak mampu bekerja dan beraktivitas 
(Tari, 2018).

Upaya pencegahan yang

dilakukan pemerintah dalam menurunkan Asam Urat kejadian tersebut dapat dilakukan dengan tindakan deteksi dini, berupa pemeriksaan yang terkait dengan penyakit rentan dialami oleh lansia. Deteksi secara dini dapat dilakukan dengan pengecekan status gizi, dan pemeriksaan kadar Asam urat. (Febriyanti et al,. 2020).

Intervensi pemberian rebusan daun salam yang dilakukan 2 kali pada pagi dan sore hari selama 20 menit yaitu sebagai bentuk upaya terapi non farmakologi untuk mengurangi rasa nyeri yang dapat mengganggu aktifitas. Daun salam memiliki kandungan flovanoid yang mampu menurunkan kadar asam urat dalam darah. (Andiani\& Chaidir 2016).

Manfaat pemberian rebusan daun salam berkhasiat mengatasi penyakit gout dengan cara menurunkan kadar asam urat dalam darah. Dalam pengobatan, daun salam digunakan untuk pengobatan kolesterol tinggi, kencing manis (diabetes melitus), tekanan darah tinggi (hipertensi), sakit mag (gastritis), diare, dan diduga kandungan kimianya mempunyai aktivitas sebagai obat asam urat (Ningtiyas \& Ricky 2016).

Lansia mengalami proses penuaan dengan begitu secara dengan progresif akan kehilangan daya tahan tubuh terhadap infeksi dan akan menumpuk semakin banyak distorsi metabolic dan structural yang disebut sebagai penyakit Hasil Penelitian yang dilakukan oleh Vechya et al.,(2019). Pada penelitian tersebut Gout artritis merupakan salah satu jenis radang sendi yang disebabkan oleh pengendapan kristal monosodium urat dalam jaringan tubuh. hasil penelitian ini menunjukkan terdapat pengaruh pemberian rebusan daun salam terhadap penurunan kadar degenerative. Penyakit Gout ini terjadi karena sistem kerja tubuh yang semakin menurun serta masih banyak pola hidup yangburuk pada lansia (Harlina, 2020) Hasil Penelitian yang dilakukan oleh Ellin (2018) pada penelitian tersebut Kadar asam urat pada lansia akan mengalami peningkatan diatas normal. Hasil penelitian sebelum pemberian air rebusan daun salam seluruh lansia memiliki kadar asam urat tidak normal sebanyak 30 lansia (100\%). Setelah pemberian air rebusan daun salam hampir seluruh lansia memiliki kadar asam urat normal sebanyak 26 lansia (86,7\%). Hasil Penelitian yang dilakukan oleh Roza \& Putri (2019). Pada penelitian tersebut Arthritis Gout merupakan peradangan pada sendi yang disebabkan oleh peningkatan kadar asam urat dalam darah, karena terganggunya metabolisme purin (hiperurisemia) dalam tubuh yang ditandai dengan nyeri sendi, sehingga dapat mengganggu aktifitas. Disamping penataksanaan secara farmakologi, penggunaan bahan herbal daun salam (Sysgium Polyanthum) dapat dijadikan alternatif untuk mengobati arthritis gout. Hasil penelitian didapatkan rata-rata kadar asam urat sebelum dan sesudah dilakukan pemberian air rebusan daun salam adalah $5.7 \mathrm{mg} / \mathrm{dl}$ dan $4,9 \mathrm{mg} / \mathrm{dl}$, berarti ada pengaruh pemberian air rebusan daun salam terhadap kadar asam urat padapenderita Arthritis Gout.

asam urat.

Hasil studi pendahuluan yang dilakukan peneliti di wilayah puskesmas Kelurahan Cengkareng Timur Kecamatan Cengkareng Jakarta Barat pada tahun 2019 memiliki jumlah penduduk lansia sebanyak 120.612 jiwa dengan 7 penyakit terbanyak salah satunya adalah Asam Urat. Data hasil survey 
di wilayah RW 03 Puskesmas Kelurahan Cengkareng Timur Kecamatan Cengkareng Jakarta Baratdengan jumlah penduduk 1.640 kepala keluarga didapatkan data distribusipenyakit asam urat adalah 239 (13,5\%), (Hasil Survey Di Puskesmas Kelurahan Cengkareng Timur, 2019).

Berdasarkan latar belakang masalah tersebut penulis tertarik untuk menyusun dan menganalisa bagaimana penerapan Terapi Pemberian Rebusan Daun Salam untuk menurunkan asam urat pada lansia diwilayah puskesmas Kelurahan Cengkareng Timur kecamatan Cengkareng Jakarta Barat.

\section{METODE}

Jenis penelitian ini adalah penelitian case study design yaitu suatu bentuk penelitian (inquary) atau studi kasus dan intervensi tentang suatu masalah yang memiliki sifat kekhususan (particulary) dengan tujuan untuk mempelajari secaraintensif mengenai unit - unit sosial seperti perhimpunan, perorangan maupun kelompok, keluarga dan bahkan masyarakat luas Menurut (Basuki Tahun 2017). Pada penelitian ini peneliti melakikan intervensi pemberian rebusan daun salam pada empat lansia penderita asam urat yaitu keempat penderita sama - sama diberikan air rebusan daun salam.

Pada penelitian ini peneliti melakukan intervensi pemberian rebusan daun salam dalam pelayanan dan asuhan keperawatan pada lansia penderita asam urat dengan karakteristik yang sama yaitu 4 klien sama - sama diberikan air rebusan daun salam dilakukan selama 15 - 20 menit, setiap $2 x$ sehari selama 6 hari.

Hasil penelitian memenuhi syarat untuk di ujikan, penelitian sudah memenuhi uji proposal dan lulus dalam uji etik penelitian ini.

HASIL

Tabel 1

Distribusi Karakteristik Responden $(n=4)$ dengan Kadar Asam Urat Sebelum diberikan Intervensi Rebusan Daun Salam di Rw 03 Kelurahan Cengkareng Timur Kecamatan Cengkareng Jakarta Barat 2021

\begin{tabular}{|c|c|c|c|c|}
\hline Responden & Usia & $\begin{array}{l}\text { Jenis } \\
\text { Kelamin }\end{array}$ & Penyakit komplikasi & $\begin{array}{l}\text { Kadar } \\
\text { Asam Urat }\end{array}$ \\
\hline R1 & 64 Tahun & Perempuan & Hipertensi, DM, Asam Urat & $8,3 \mathrm{mg} / \mathrm{dL}$ \\
\hline R2 & 70 Tahun & Laki-laki & $\begin{array}{l}\text { Hipertensi, Kolestrol, Asam } \\
\text { Urat }\end{array}$ & $9,0 \mathrm{mg} / \mathrm{dL}$ \\
\hline R3 & 55 Tahun & Perempuan & $\begin{array}{l}\text { DM, Hipertensi, Kol, Asam } \\
\text { Urat }\end{array}$ & $8,4 \mathrm{mg} / \mathrm{dL}$ \\
\hline R4 & 58 Tahun & Laki-laki & $\begin{array}{l}\text { DM, Hipertensi, Kol, Asam } \\
\text { Urat }\end{array}$ & $10,4 \mathrm{mg} / \mathrm{dl}$ \\
\hline
\end{tabular}

Sumber : Data Primer 2021

Tabel 1 menunjukan bahwa gambaran lansia usia 55 - 70 tahun. Memiliki penyakit komplikasi
(Hipertensi, Diabetes Militus dan Kolestrol) yang menjadi responden sebanyak 4 orang. 
Tabel 2

Kadar Asam Urat karakteristik Responden $(n=4)$ Sebelum dan SesudahPemberian Rebusan Daun Salam di Rw 03 Kelurahan Cengkareng Timur Kecamatan Cengkareng Jakarta Barat 2021

\begin{tabular}{|c|c|c|c|}
\hline Responden & $\begin{array}{l}\text { Sebelum Pemberian } \\
\text { Rebusan Daun Salam }\end{array}$ & $\begin{array}{l}\text { Sesudah Pemberian } \\
\text { Rebusan Daun Salam }\end{array}$ & Keterangan \\
\hline R1 & $8,3 \mathrm{mg} / \mathrm{dL}$ & $5,2 \mathrm{mg} / \mathrm{dl}$ & $\begin{array}{l}\text { Turun, tidak ada } \\
\text { nyeri pada kaki }\end{array}$ \\
\hline R2 & $9,0 \mathrm{mg} / \mathrm{dL}$ & $7,2 \mathrm{mg} / \mathrm{dL}$ & $\begin{array}{l}\text { Turun, nyeri pada } \\
\text { kaki berkurang }\end{array}$ \\
\hline R3 & $8,4 \mathrm{mg} / \mathrm{dL}$ & $6,5 \mathrm{mg} / \mathrm{dL}$ & $\begin{array}{l}\text { Turun, tidak ada } \\
\text { nyeri pada kaki }\end{array}$ \\
\hline R4 & $10,4 \mathrm{mg} / \mathrm{dL}$ & $6,0 \mathrm{mg} / \mathrm{dL}$ & $\begin{array}{l}\text { Turun, tidak ada } \\
\text { nyeri pada kaki }\end{array}$ \\
\hline
\end{tabular}

Sumber : Data Primer 2021

Berdasarkan tabel 2 diatas menunjukan bahwa dari 4 responden sebelum pemberian rebusan daun salam pengukuran nilai pengukuran kadar asam urat rerata diatas 9,0 $\mathrm{mg} / \mathrm{dl}$. Setelah dilakukan pemberian

\section{PEMBAHASAN}

1. Sebelum dan Sesudah Pemberian Rebusan Daun Salam

Karakteristik responden lansia usia 55 - 70 tahun. Memiliki penyakit komplikasi (Hipertensi, Diabetes Militus dan Kolestrol) yang menjadi responden 4 orang di Rw 03 Kelurahan Cengkareng Timur Kecamatan Cengkareng Jakarta Barat. Responden 1 memiliki penyakit komplikasi Asam Urat, Hipertensi dan Diabetes Militus. Responden 2 memiliki penyakit komplikasi Asam Urat, Hipertensi, dan Kolestrol. Responden 3 memiliki penyakit komplikasi Asam Urat, Hipertensi, Diabetes Miletus, dan Kolestrol. Responden 4 memiliki penyakit komplikasi Asam Urat, Hipertensi, Diabetes Miletus, dan Kolestrol.

Penelitian ini sejalan dengan penelitian andriani \& Chaidir (2016) yaitu dilakukan pemeriksaan gula darah, hipertensi, dan kolestrol agar rebusan daun salam terjadi penurunan kadar asam urat dengan rerata $6,5 \mathrm{mg} / \mathrm{dl}$ dan tidak ada nyeri pada kaki setelah dilakukan selama 6 hari.

tidak terjadi penurunan (efek hipoglikemik) maka peneliti harus melakukan pemerikasaan gula darah, hipertensi, dan kolestrol sebelum diberikan air rebusan daun salam pada responden.

Data hasil analisis mengenai pemberian rebusan daun salam. menunjukan bahwa dari 4 responden sebelum pemberian rebusan daun salam pengukuran nilai pengukuran kadar asam urat rerata diatas 9,0 $\mathrm{mg} / \mathrm{dl}$. Setelah dilakukan pemberian rebusan daun salam tidak mengalami penurunan yang signifikan kadar asam urat dan nyeri masih ada pada hari pertama. Hari kedua menunjukan bahwa dari 4 responden sebelum pemberian rebusan daun salam pengukuran nilai pengukuran kadar asam urat rerata diatas 9,0 $\mathrm{mg} / \mathrm{dl}$. Setelah dilakukan pemberian rebusan daun salam responden 1 yang mengalami penurunan kadar asam urat dari $8,3 \mathrm{mg} / \mathrm{dl}$ menjadi 
8,0 dan responden 4 mengalami penurunan kadar asam urat dari 10,0 $\mathrm{mg} / \mathrm{dl}$ menjadi $9,6 \mathrm{mg} / \mathrm{dl}$ sedangkan pada responden 2 dan responden 3 tidak ada penurunan kadar asam urat karena masih mengkonsumsi makanan tinggi purin nyeri masih ada pada hari kedua.

Penelitian ini sejalan dengan penelitian Arifki et al., (2021) yaitu pada hari pertama belum ada penurunan kadar asam urat yang signifikan terdapat penurunan kadar asam urat pada hari kedua yaitu rerata hasil dari $9,0 \mathrm{mg} / \mathrm{dl}$ menjadi rerata $8,7 \mathrm{mg} / \mathrm{dl}$. Pemberian rebusan daun salam dapat dijadikan alternatif perawatan penyakit asam urat yang dilakukan dua kali selama 15 - 20 menit, agar efektif untuk menurunkan kadar asam urat.

Hari ketiga menunjukan bahwa dari 4 responden sebelum pemberian rebusan daun salam pengukuran nilai pengukuran kadar asam urat rerata diatas $8,7 \mathrm{mg} / \mathrm{dl}$. Setelah dilakukan pemberian rebusan daun salam responden 1 yang mengalami penurunan kadar asam urat dari 7,9 $\mathrm{mg} / \mathrm{dl}$ menjadi $7,7 \mathrm{mg} / \mathrm{dl}$ dan responden 4 mengalami penurunan kadar asam urat dari $9,2 \mathrm{mg} / \mathrm{dl}$ menjadi $8,5 \mathrm{mg} / \mathrm{dl}$, sedangkan pada responden 2 dan responden 3 tidak ada penurunan kadar asam urat karena tidak mematuhi diet rendah purin nyeri masih ada pada hari ketiga.

Penelitian ini sejalan dengan penelitian Setianingrum et al., (2017) terdapat pengaruh pemberian rebusan daun salam terhadap penurunan kadar asam urat pada lansia pada hari ketiga yaitu dengan rerata kadar asam urat sebelum diberikan $8,7 \mathrm{mg} / \mathrm{dl}$ dan terjadi penurunan kadar asam urat setelah pemberian rebusan daun salam menjadi $8,5 \mathrm{mg} / \mathrm{dl}$.

Hari keempat menunjukan bahwa dari 4 responden sebelum pemberian rebusan daun salam pengukuran nilai pengukuran kadar asam urat rerata diatas $8,0 \mathrm{mg} / \mathrm{dl}$. Setelah dilakukan pemberian rebusan daun salam responden 1 yang mengalami penurunan kadar asam urat dari $7,0 \mathrm{mg} / \mathrm{dl}$ menjadi $6,5 \mathrm{mg} / \mathrm{dl}$, responden 2 mengalami penurunan kadar asam urat dari 8,8 $\mathrm{mg} / \mathrm{dl}$ menjadi $8,5 \mathrm{~m} / \mathrm{dl}$, responden 3 mengalami penurunan kadar asam urat dari $8,4 \mathrm{mg} / \mathrm{dl}$ menjadi 8,0 $\mathrm{mg} / \mathrm{dl}$ dan responden 4 mengalami penurunan kadar asa urat dari 8,0 $\mathrm{mg} / \mathrm{dl}$ menjadi $7,5 \mathrm{mg} / \mathrm{dl}$ nyeri masih ada.

Penelitian ini sejalan dengan penelitian Alvita \& Fidora (2018) terdapat pengaruh pemberian rebusan daun salam untuk menurunkan kadar asam urat pada hari keempat dengan menunjukan bahwa rerata kadar asam urat setelah diberikan rebusan daun salam sebelum pemberian rebusan $8,1 \mathrm{mg} / \mathrm{dl}$ dan sesudah pemberian rebusan daun salam menjadi 7,6 $\mathrm{mg} / \mathrm{dl}$.

Hari kelima menunjukan bahwa dari 4 responden sebelum pemberian rebusan daun salam pengukuran nilai pengukuran kadar asam urat rerata diatas $7,3 \mathrm{mg} / \mathrm{dl}$. Setelah dilakukan pemberian rebusan daun salam responden 1 yang mengalami penurunan kadar asam urat dari $6,0 \mathrm{mg} / \mathrm{dl}$ menjadi $5,5 \mathrm{mg} / \mathrm{dl}$, responden 2 mengalami penurunan kadar asam urat dari 8,3 $\mathrm{mg} / \mathrm{dl}$ menjadi $7,7 \mathrm{mg} / \mathrm{dl}$, responden 3 mengalami penurunan kadar asam urat dari $7,8 \mathrm{mg} / \mathrm{dl}$ menjadi 7,0 $\mathrm{mg} / \mathrm{dl}$ dan responden 4 mengalami penurunan kadar asam urat dari 7,4 $\mathrm{mg} / \mathrm{dl}$ menjadi $6,9 \mathrm{mg} / \mathrm{dl}$ nyeri berkurang.

Penelitian ini sejalan dengan penelitian yang dilakukan Febriyanti \& Andhika (2018) terdapat pengaruh pemberian rebusan daun salam (syzygium polyanthum) terhadap kadar asam urat pada lansia yaitu adanya penurunan kadar asam urat 
setelah dilakukan intervensi selama 5 hari dengan rerata kadar asam urat $7,3 \mathrm{mg} / \mathrm{dl}$.

Hari keenam menunjukan bahwa dari 4 responden sebelum pemberian rebusan daun salam pengukuran nilai pengukuran kadar asam urat rerata diatas $6,5 \mathrm{mg} / \mathrm{dl}$. Setelah dilakukan pemberian rebusan daun salam responden 1 mengalami penurunan kadar asam urat dari $5,5 \mathrm{mg} / \mathrm{dl}$ menjadi 5,2 $\mathrm{mg} / \mathrm{dl}$, responden 2 mengalami penurunan kadar asam urat dari 7,6 $\mathrm{mg} / \mathrm{dl}$ menjadi $7,2 \mathrm{mg} / \mathrm{dl}$, responden 3 mengalami penurunan kadar asam urat dari $7,0 \mathrm{mg} / \mathrm{dl}$ menjadi 6,5 $\mathrm{mg} / \mathrm{dl}$, responden 4 mengalami penurunan kadar asam urat dari 6,7 $\mathrm{mg} / \mathrm{dl}$ menjadi $6,0 \mathrm{mg} / \mathrm{dl}$ dan nyeri berkurang

Penelitian ini sejalan dengan penelitian yang dilakukan Widiyono et al., (2020) terhadap pengaruh pemberian rebusan daun salam (syzygium polyanthum) dalam menurunkan kaadar asam urat pada lansia, yaitu adanya penurunan kadar asam urat pada hari ke enam dengan rerata kadar asam urat sebelum pemberian rebusan daun salam $6,5 \mathrm{mg} / \mathrm{dl}$ menjadi $6,0 \mathrm{mg} / \mathrm{dl}$ setelah diberikan rebusan daun salam.

\section{KESIMPULAN}

Penelitian pemberian rebusan daun salam pada penderita asam telah menunjukan penurunan kadar asam urat yang signifikan pada hari ke enam. Sebelum dilakukan intervensi rebusan daun salam pada empat responden dengan rerata kadar asam urat $9,0 \mathrm{mg} / \mathrm{dl}$ dan sesudah pemberian rebusan daun salam terjadi penurunan kadar asam urat pada empatresponden dengan nilai rerata kadarasam urat $6,0 \mathrm{mg} / \mathrm{dl}$. Semua responden mengalami penurunan kadar asam urat setelah pemberian rebusan daun salam.

\section{SARAN}

Bagi Pengambil Kebijakan

Kesehatan,

Bagi puskesmas cengkareng timur dapat mempertimbangkan untuk melakukan intervensi pemberian rebusan daun salam sebagai penatalaksanaan pasien asam urat sebagai progran pelayanan kesehatan.

Bagi Institusi

Dapat memberikan informasi menjaadi acuan intervensi keperawatan untuk masalah kesehatan lansia khususnya penderita gout atau asam urat. Metode pemberian rebusan daun salam dapat menjadi salah satu bahan materi yang diberikan bagi mahasiswa sebagai intervensi keperawatan gerontik khusnya pada lansia penderita asam urat.

Bagi Peneliti Selajutnya

Perlu adanya penambahan penambahan proses intervensi pemberian rebusan daun salam dalam rangka mengembangkan dan penyempurnaan intervensi keperawatan dalam mencegah penyakit gout pada lansia.

Bagi Keluarga dan lansia

Pihak keluarga dapat terus mendampingi lansia untuk melanjutkan intervensi dan implementasi pemberian rebusan daun salam sebagai upaya pencegahan penderita asam urat bagi Lansia.

\section{DAFTAR PUSTAKA}

Alvita, Helvi \& Fidora, Irma. (2018). Pengaruh Pemberian Rebusan Daun Salam terhadap Penurunan Kadar Asam Urat Lansia. Jurnal Menara Medika Vol 1 No 1.

Andriani, Aida \& Reny, Chaidir. (2016). Pengaruh pemberian rebusandaun salam (Syzgium Polyanthum) 
urat. Bukittinggi. Jurnal IPTEKS Terapan Vol.10 112 119.

Arifki et.,al. (2021). Penggunaan daun salam terhadap klien asam urat untukmenurunkan kadar asam urat dikelurahan Gunung Agung. Lampung. Jurnal Kreativitas PKM Vol.4(1).

Basuki, H. (2017). Pengaruh Akses Pelayanan Kesehatan. Buletin Penelitian Sistem Kesehatan.

Depkes RI. (2018). Riset Kesehatan Dasar.Jakarta: Departemen

Ellin. A. (2018). Pengaruh Pemberian Air Rebusan Daun Salam terhadap Penurunan Kadar Asam Uratpada Lansia. Insan Cendikia Medika Jombang.

Eni, A., Ari, P. D., \& Riri, N. FaktorFaktor yang berhubungan dengan kejadian gout arthritis masyarakat melayu. Jurnal JOMFKp, 5(2),683-692 (2018).

Febriyanti, F \& Andhika, M. (2018). Pemberian Rebusan Daun Salam (Syzygium Polyanthum) Terhadap Kadar Asam Urat Pada Lansia. Menara Ilmu, 12(10).

Febriyanti, T., Nuhadriyah, W. D., \& $\mathrm{Ni}$ Luh, D. A. (2020). Hubungan Kemampuan Pengetahuan Diet Rendah Purin dengan Kadar Asam Urat. Malang. Jurnal Ners LENTERA, Vol.8(1).

Harlina, P. R, Arifin, Zainul \& Anita, R. (2020). Gambaran kadar asam urat pada lansia. Jombang. Insan Cendekia Medika.

Jaliana, J., \& Suhadi, S. (2018). Faktor - Faktor Yang Berhubungan Dengan Kejadian Asam UratPada Usia 20-44 Tahun Di Rsud Bahteramas Provinsi
Sulawesi Tenggara Tahun 2017. Jurnal IImiah Mahasiswa Kesehatan Masyarakat,3(2).

Kementrian Kesehatan Republik Indonesia. (2018). Riset Kesehatan Dasar Prevalensi Penyakit Sendi Berdasarkan Diagnosa.

Riset Kesehatan Dasar. (2018). Laporan Provinsi DKI Jakarta

Roza, M \& Putri, Dafriani. (2019). Pengaruh pemberian air rebusan daunsalam terhadap penurunan kadar asam urat pasien Artritis Gout. Jurnal Kesehatan Saintika Meditory Vol.2(1).

Setianingrum, P. D, Dwi Istika, \& Kurnia, R. D. (2017). Pemberian Rebusan Daun Salam Terhadap Penurunan Kadar Asam Urat Pada Penderita Asam Urat Di Dusun Kadisoro Desa Gilangharjo Kecamatan Pandak Kabupaten Bantul. Yogyakarta: STIKES Surya Global.

Tari, S. (2018). Pengaruh rebusan daun salam (Syzgium Polyanthum Wight) terhadap penurunan kadarasam urat pada Lansia dipanti Sosial Penyantunan Lanjut Usia Budi Agung Kupang. Kupang. STIkes Husada.

Vechya, Z. L. P, Oroh, Wenda \& Hendro, Bidjuni. (2019). Pengaruh Pemberian Daun Salam Terhadap Penurunan Kadar Asam Urat Pada penderita Gout Artritis di Wilayah Kerja Puskesmas Ranotana Weru. Sulawesi Utara. E. Journal Keperawatan, Vol.7(1).

Widiyono et.,al. (2020). Pengaruh Pemberian Rebusan Daun Salam Terhadap Penurunan Kadar Asam UratPada Lansia Di Posyandu Lansia Desa 
Desember [MAHESA: MALAHAYATI HEALTH STUDENT JOURNAL, P- ISSN: 2746-198X
Ngembat Padas Sragen. Jurnal Perawat Indonesia Vol. 4(1).

World Health Organization. (2017).
Methods and Data Sources Global Burden of Diasese Estimates 2000-2015 